\title{
Effect of Dye Structure on the Photodegradation Kinetic Using $\mathrm{TiO}_{2}$ Nanoparticles
}

\author{
Hawraa Ayoub' ${ }^{1}$ Mounir Kassir ${ }^{2}$, Mohammad Raad², Houssein Bazzi², Akram Hijazi2 \\ ${ }^{1}$ Laboratory of Materials, Catalysis, Environment and Analytical Methods, Faculty of Sciences I, Lebanese University, Beirut, \\ Lebanon \\ ${ }^{2}$ Platform for Research and Analysis in Environmental Sciences (PRASE), Doctoral School of Science and Technology (EDST), \\ Lebanese University, Beirut, Lebanon \\ Email: *mounir.kassir@ul.edu.lb
}

How to cite this paper: Ayoub, H., Kassir, M., Raad, M., Bazzi, H. and Hijazi, A. (2017) Effect of Dye Structure on the Photodegradation Kinetic Using $\mathrm{TiO}_{2}$ Nanoparticles. Journal of Materials Science and Chemical Engineering, 5, 31-45.

https://doi.org/10.4236/msce.2017.56004

Received: May 18, 2017

Accepted: June 26, 2017

Published: June 29, 2017

Copyright (c) 2017 by authors and Scientific Research Publishing Inc. This work is licensed under the Creative Commons Attribution International License (CC BY 4.0).

http://creativecommons.org/licenses/by/4.0/

\begin{abstract}
In this study the effect of $\mathrm{pH}$, adsorption behavior and the chemical structures of two dyes (Methyl Orange and Bromothymol Blue) on the photodegradation rate constant, was investigated. Adsorption isotherm shows that the adsorption amount of dyes on $\mathrm{TiO}_{2}$ surface is highly related to the $\mathrm{pH}$ of the solution and to the $\mathrm{pKa}$ of each dye. In acidic medium the adsorption percentage of Methyl Orange on $\mathrm{TiO}_{2}$ surface was $76 \%$ facing $5 \%$ for Bromothymol Blue. The kinetic study shows compatibility between the degradation rate constant and the adsorption percentage on the surface. In basic medium the adsorption percentage of Methyl orange and Bromothymol Blue is similar while the degradation rate of Methyl orange is two times faster than that of Bromothymol Blue which reveals the role of chemical structure in the photodegradation rate.
\end{abstract}

\section{Keywords}

Photocatalysis, Titanium Dioxide, Adsorption, Dyes, Depollution

\section{Introduction}

Dyes decomposition from textile wastewater is recognized as an important environmental treatment due to their potential toxicity and coloration [1]. The characteristics of these dye compounds have generated some challenging environmental problems, such as reducing the percentage of light penetrating into the water which reduces photosynthetic activity in aquatic media. A low concentration of visible dye is intolerable and can cause a health hazard for humans [2]. Various physical, chemical and biological methods such as adsorption, photoly- 
sis, chemical precipitation, chemical oxidation and reduction, electrochemical precipitation have been employed for the removal of dyes from wastewater [3] [4] [5] [6].

Among these approaches, photodegradation is considered as a promising technology because it is a versatile, low-cost and environmentally benign treatment for most of pollutants. They are based on the generation of the strongly oxidizing hydroxyl radicals $(\mathrm{OH} \cdot)$. These radicals are characterized by a little selectivity of attack, and are able to oxidize a variety of organic compounds that could be present in water and wastewater, due to their high oxidative capacity (redox potential of $\mathrm{OH}$ : $\mathrm{E} 0=2.8 \mathrm{~V}$ ), yielding $\mathrm{CO}_{2}$ and inorganic ions [7].

Advanced oxidation processes (AOPs) are based on the photogeneration of valence band holes $(\mathrm{h}+)$ and conduction band electrons $(\mathrm{e}-)$ which react with water and oxygen to form highly reactive species such as $\mathrm{OH} \cdot \mathrm{H}_{2} \mathrm{O}_{2}$ and $\mathrm{O}_{2^{-}}-$on the semiconductors surface. These prepared species is strong enough to break the different bonds in the organic pollutants. Hence, AOPs are effective and rapid methods to remove toxic and bio-refractory pollutants such as dyes in wastewaters [8].

With respect to other photocatalysts, $\mathrm{TiO}_{2}$ has so far been considered as one of the most preferred materials due to its non-toxicity, resource availability, low-cost and high stability [9]. It is capable of decomposing a wide variety of organics and inorganics in both liquid and gas phases, when its aqueous form is irradiated with light energy greater than its band gap energy $(\mathrm{Eg}=3.2 \mathrm{ev})[10]$.

Generally the photodegradation rate is strongly related to the adsorption affinity of dyes on the catalyst surface [11]. The affinity between the catalyst $\mathrm{TiO}_{2}$ and pollutants is an important factor in enhancing the photodegradation efficiency [12].

A few research projects focused on the relation between the chemical structure of dyes molecules and its resistance to the photocatalytic degradation [13] [14] [15].

In the present study, the effect of chemical structure of organic dyes on the photodegradation rate was investigated using $\mathrm{TiO}_{2}$ catalyst. Methyl orange (MO) and Methyl Orange (BBT) were chosen as model organic pollutants since they contain different functional groups. We are going to discuss the effect of $\mathrm{pH}$ on their adsorption and degradation, to compare the rate constant of degradation of each dye according to their chemical structure and stability. The molecular structures of MO and BBT in basic and acidic medium are shown in Figure 1, where their Pka values are respectively 3.4 and 7.1 .

\section{Materials and Methods}

\subsection{Materials}

Titanium dioxide powder P25 was employed since it remained the state of the art photocatalyst [16] [17]. It was supplied by Evonik-Degussa. The particle diameter, estimated by transmission electron microscopy (TEM), was approximately equal to $25-30 \mathrm{~nm}$. 


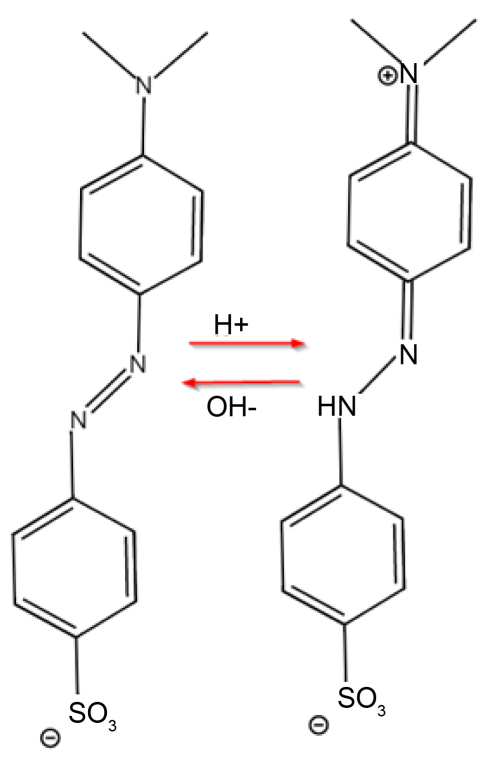

Methyl Orange<smiles>CC1=C(Br)C(=O)C(C(C)C)=C/C1=C(\c1ccccc1S(=O)(=O)[O-])c1cc(C(C)C)c([O-])c(Br)c1C</smiles>

Bromothymol blue

Figure 1. Chemical structure of Methyl Orange and Bromothymol Blue.

\subsection{Surface Characterization}

The chemical and surface properties of the solid samples were characterized by, Fourier transform infrared spectroscopy (FTIR), X ray diffraction and electrophoretic mobility.

The kinetic study was followed by measuring the absorbance in visible for the colored dyes. Fourier transform infrared spectroscopy was used to analyze the surface chemistry of the powders. Diffuse reflectance (DRIFT) spectra were recorded using a Fourier transform infrared spectrometer (Bruker IFS 55). FTIR experiments were also carried out in transmission mode by means of a Fourier transform infrared spectrometer (JASCO TF/IR 6300 type A).

UV/visible diffuse reflectance spectra were obtained using a UV/vis spectrophotometer (Shimadzu).

Electrophoretic mobilities were measured with Zetaphorometer ZIII from SEPHY-CAD society instrument. The solutions for zeta potential measurements contained $10 \mathrm{mg} / \mathrm{L}$ of $\mathrm{TiO}_{2}$ dispersed in $10^{-3} \mathrm{M} \mathrm{NaCl}$ aqueous solution. Prior to each measurement, the suspensions were sonicated for $2 \mathrm{~min}$.

The phase structure of the $\mathrm{TiO}_{2}-\mathrm{P} 25$ photocatalyst was examined by X-ray diffraction (XRD) using X-ray diffractometer with $\mathrm{Cu} \mathrm{K} \alpha$ radiation $(\lambda=0.15406$ $\mathrm{nm})$.

\subsection{Photodegradation Experiment}

Experiments were carried out, at room temperature, in a glass Petri dish (di- 
ameter $5.8 \mathrm{~cm}$ ) reactor with $80 \mathrm{~mL}$ capacity placed on a magnetic stirrer. The light source was provided by a mercury lamp positioned outside the reactor and parallel to it, emitting in the near-UV. The incident light intensity reaching the top of the reacting suspension was equal to 10 - 6 Einstein $\mathrm{L}^{-1} \cdot \mathrm{s}^{-1}$.

The catalyst was mixed with the pollutant aqueous solution (Methyl Orange or Bromothymol Blue) under stirring. For all experiments, the photocatalyst content and the initial pollutant concentration were equal to $1 \mathrm{~g} / \mathrm{L}$ and $10 \mathrm{mg} / \mathrm{L}$, respectively. According to the $\mathrm{pKa}$ values and in aims to obtain a homogenous structure of each dye (conjugate acid or base), the initial $\mathrm{pH}$ was adjusted to the desired value ( $\mathrm{pH} 3$ or 10) through $\mathrm{NaOH}$ or $\mathrm{HCl}$ addition. At the beginning of each experiment, the suspension containing the pollutant was magnetically stirred in the dark for $1 \mathrm{~h}$ to reach the adsorption/desorption equilibrium [18]. After this, the solution was then irradiated using UV light under continuous magnetic stirring. At different times, $3 \mathrm{~mL}$ of the suspension were withdrawn with a glass syringe and the catalyst particles were separated from the liquid by filtration (0.1 nm PTFE Millipore filter). A sample was taken at the end of the dark adsorption period (irradiation time $=0$ ). The pollutant concentrations were analyzed by a UV/vis spectrophotometer. For Methyl Orange, the absorbance value in acidic medium is at the wavelength of $464 \mathrm{~nm}$ while at basic medium is $520 \mathrm{~nm}$ [19] [20] [21]. For Bromothymol Blue, the absorbance value in acidic medium is at the wavelength of $428 \mathrm{~nm}$ while at basic medium is $616 \mathrm{~nm}$ [22].

It appeared important to perform experiments in the absence of direct photolysis in order to gain information about the photocatalytic process. Under UV light irradiation but in the absence of titania, the results indicated no degradation of the pollutants (Methyl Orange or Bromothymol Blue). The degradation remained also negligible in the absence of UV light (but in the presence of $\mathrm{TiO}_{2}$ ). A significant degradation of the contaminants occurred only in the simultaneous presence of titania and UV light.

\section{Results and Discussion}

\subsection{Characterization of Titanium Dioxide}

Figure 2 displays the XRD pattern of the $\mathrm{TiO}_{2} \mathrm{P} 25$ particles. The curve shows typical pattern of the anatase powder of good quality (good crystallinity). The peaks located at 25.4, 37.8, 48.0 and 54.5 respond to the (101), (004), (200), (105 and 211) planes of the anatase phase (JCPDS 21-1272), and that located at 27.5, $36.1,54.4$ respond to the (110), (101), (211) planes of the rutile phase (JCPDS 21-1276), respectively.

The FTIR is mainly used to analyze the $\mathrm{TiO}_{2}$ surface. Figure 3 displays the DRIFT spectra of bare $\mathrm{TiO}_{2}$. The analyses were performed at atmospheric pressure, the spectra of titania powders showing a broadband in the $3800-2700 \mathrm{~cm}^{-1}$ region (peak around $3400 \mathrm{~cm}^{-1}$ ) with an emergent peak at $3692 \mathrm{~cm}^{-1}$, three bands at 1620 , and $1420 \mathrm{~cm}^{-1}$, and a large band at around $670 \mathrm{~cm}^{-1}$. The broad vibration band between 3650 and $2600 \mathrm{~cm}^{-1}$ is associated with the $\mathrm{OH}$ stretching mode of water molecules (physisorbed molecular water), while that at $1620 \mathrm{~cm}^{-1}$ 


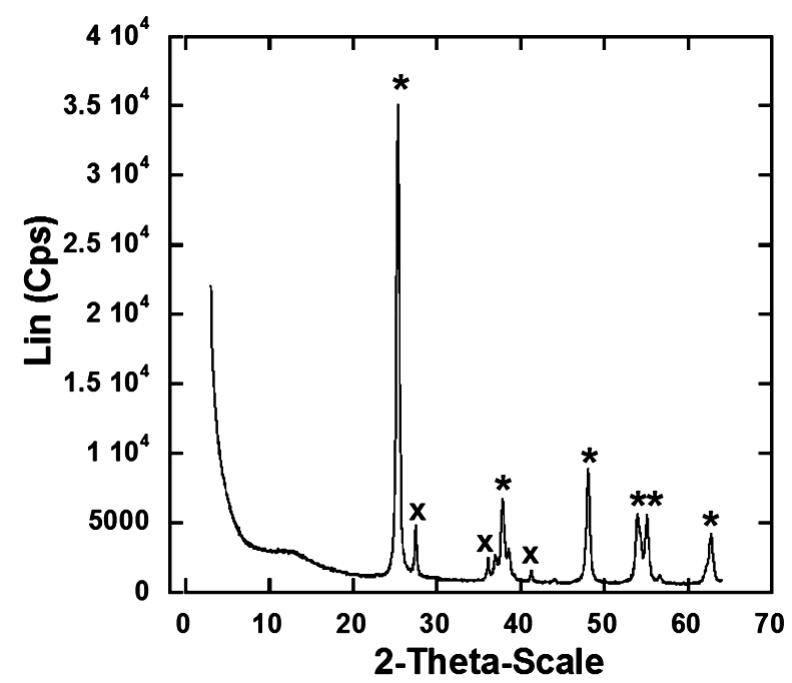

Figure 2. X-ray diffraction pattern of $\mathrm{TiO}_{2} \mathrm{P} 25$; ${ }^{\star}$ Anatase, $\times$ Rutile.

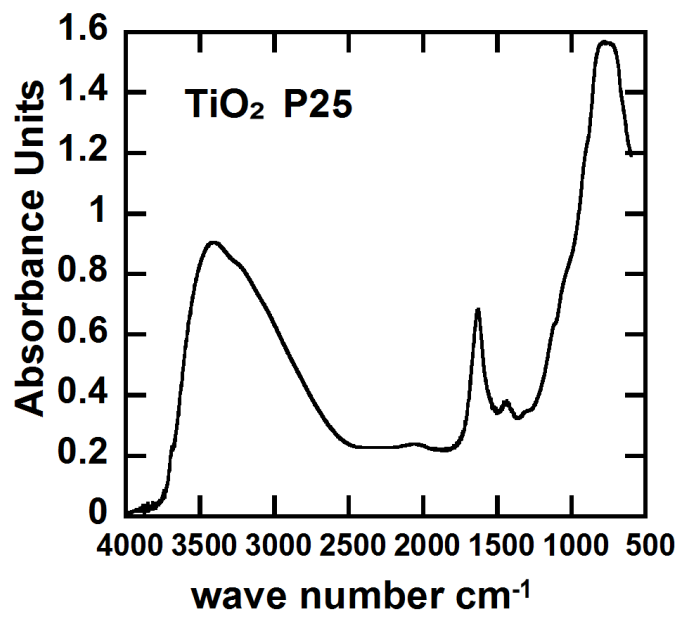

Figure 3. Infra red transmission spectra of $\mathrm{TiO}_{2} \mathrm{P} 25$.

is assigned to their bending modes. According to various studies carried out to associate the IR bands to specific groups adsorbed on the oxide surfaces [23] [24] the bands in the $3800-3600 \mathrm{~cm}^{-1}$ region are due to the stretching modes of different types of free hydroxyl groups adsorbed on the crystalline surfaces of titania or on defects located on specific surfaces [24] [25]. The peak at $3692 \mathrm{~cm}^{-1}$ is assigned to hydroxyl groups chemisorbed on the defects of specific crystal faces of anatase. The bands in the range $1600-1300 \mathrm{~cm}^{-1}$ are generally associated with carbonate groups; thus, the bands at $\sim 1420 \mathrm{~cm}^{-1}$ are assigned to carbonate species formed by the adsorption of atmospheric $\mathrm{CO}_{2}$ [26] [27]. Absorption in the range $1000-600 \mathrm{~cm}^{-1}$ is due to the surface vibrations of the Ti-O bonds.

Zeta potential measurements were used to quantify the conditions leading to the stability of $\mathrm{TiO}_{2}$ dispersions as well as the surface charge. The variation of the zeta potential is shown in Figure 4.

The $\mathrm{pH}$ variation from 3 to 10 was accompanied with a variation of zeta potential between $+35 \mathrm{mV}$ in acidic medium to around $-45 \mathrm{mV}$ in basic medium . 
The isoelectric point of $\mathrm{TiO}_{2}$ nanoparticles was $\mathrm{pH}$ 6.2, which was similarly reported by Zhao et al. [28]. Rather than stability of our $\mathrm{TiO}_{2}$ nanoparticles in basic medium these results reveals the positive surface charge of $\mathrm{TiO}_{2}$ in acidic medium $(\mathrm{pH}<5.2)$ and negative charge in basic medium $(\mathrm{pH}>7.2)$.

\subsection{Adsorption Study over $\mathrm{TiO}_{2}$ Surface}

The adsorption of Methyl Orange over $\mathrm{TiO}_{2}$ surface was studied at different $\mathrm{pH}$ values. Figure 5 shows the adsorption capacity Qe of $\mathrm{MO}$ as a function of equilibrium concentration $\mathrm{Ce}$ at $\mathrm{pH}=3$, and 10 .

All adsorption isotherms presents an increasing shape, (increasing of quantity adsorbed in mg per $\mathrm{g}$ of adsorbent), which decreases gradually to reach a plateau as a function of $\mathrm{Ce}$ (Concentration of adsorbate at equilibrium).

The highest quantity of Methyl Orange adsorbed was observed at $\mathrm{pH}$ 3, which is $\mathrm{Qe} \max =36.4 \mathrm{mg} / \mathrm{g}$ followed by $\mathrm{pH} 10$ for $\mathrm{Qe}=13.8 \mathrm{mg} / \mathrm{g}$ and the lowest

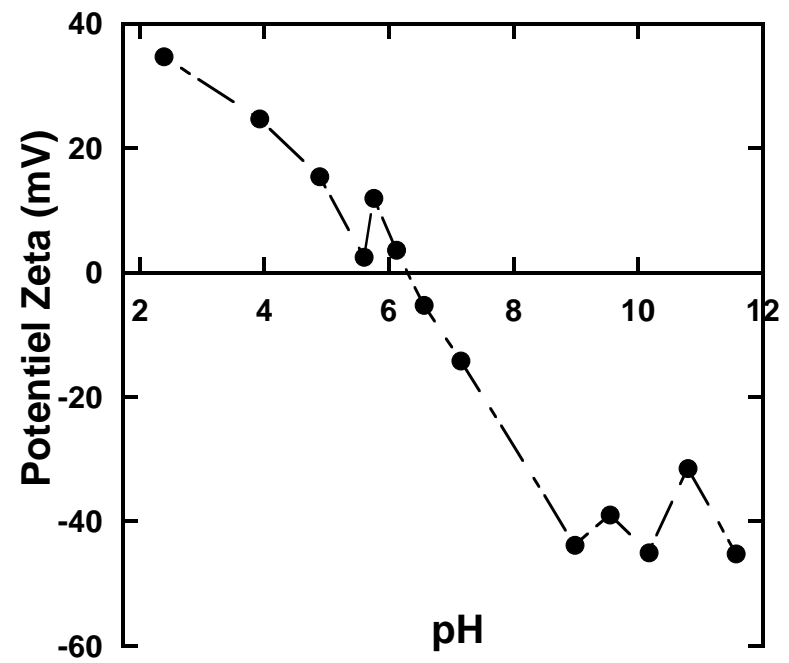

Figure 4. Zeta potential of $\mathrm{TiO}_{2} \mathrm{P} 25$ versus $\mathrm{pH}$.

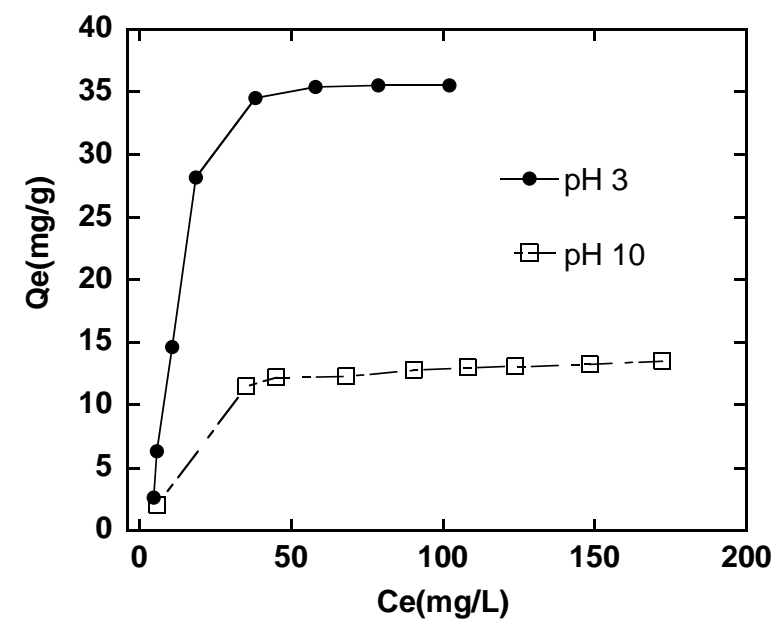

Figure 5. Adsorption isotherm of Methyl Orange on $\mathrm{TiO}_{2}$ $\mathrm{P} 25$ at different $\mathrm{pH}$. 
amount was for $\mathrm{pH}$, Qe $=7.2 \mathrm{mg} / \mathrm{g}$ of $\mathrm{TiO}_{2}$.

At $\mathrm{pH} 3$, where $\mathrm{pH}<\mathrm{PZC} \mathrm{TiO}_{2}$, they are mainly present in the forms of Ti$\mathrm{OH}$ and/or $\mathrm{Ti}-\mathrm{OH}^{2+}$, resulting in the formation of hydrogen bonds with $\mathrm{MO}$ molecules. In addition, MO is a polar molecule, and it could be adsorbed on the surface of $\mathrm{TiO}_{2}$ via van der Waals force. On the other hand, $\mathrm{O}, \mathrm{N}$ and $\mathrm{S}$ atoms in MO could form hydrogen bonds due to their high electronegativity with the surface hydroxyl groups of $\mathrm{TiO}_{2}$. Therefore at $\mathrm{pH}$, we think that both van der Waals force and hydrogen bond formation are contributive to MO adsorption [29].

At $\mathrm{pH} 10$, where $\mathrm{pH}>\mathrm{PZC}$, the surface hydroxyl groups of $\mathrm{TiO}_{2}$ will be dissociated to form TiO-; thus electrostatic repulsion between negatively charged MO molecules and $\mathrm{TiO}-$ is obtained, leading to lower adsorption capacity. Then the adsorbed percentage for $\mathrm{MO}$ in the low $\mathrm{pH}$ region is greater than in the high $\mathrm{pH}$ region.

Figure 6 represents the adsorption isotherm of BTB at $\mathrm{pH} 10$ and 3. Both isotherms show an ascending shape. The isotherm of basic medium similar to $\mathrm{S}$ shape with a higher adsorbed quantity which close $40 \mathrm{mg} / \mathrm{g}$ of $\mathrm{TiO}_{2}$ against approximately $25 \mathrm{mg} / \mathrm{g}$ in acidic medium.

At $\mathrm{pH} 3$, the BTB molecule with an apparent neutral charge is adsorbed directly on $\mathrm{TiOH}^{2+}$ surface by hydrogen bonding. While at $\mathrm{pH} 10$ the BTB starts with a very low adsorption amount due to the repulsion between the negative charged $\mathrm{BTB}$ and $\mathrm{TiO}^{2-}$ surface. After $40 \mathrm{mg} / \mathrm{L}$ of equilibrium concentration the adsorbed quantity increased rapidly where the sharp change in the slop reflect the variation in the nature of the surface and enhances the proposition of the formation of multilayer of Bromothymol Blue by van der Waals forces.

Langmuir and Freundlich adsorption models, two well-known models, were employed to the analysis of our isotherm at $\mathrm{pH}$ 3. For this, the following Equations (1) and (2) were used for Langmuir and Freundlich adsorption model studies, respectively [30] [31].

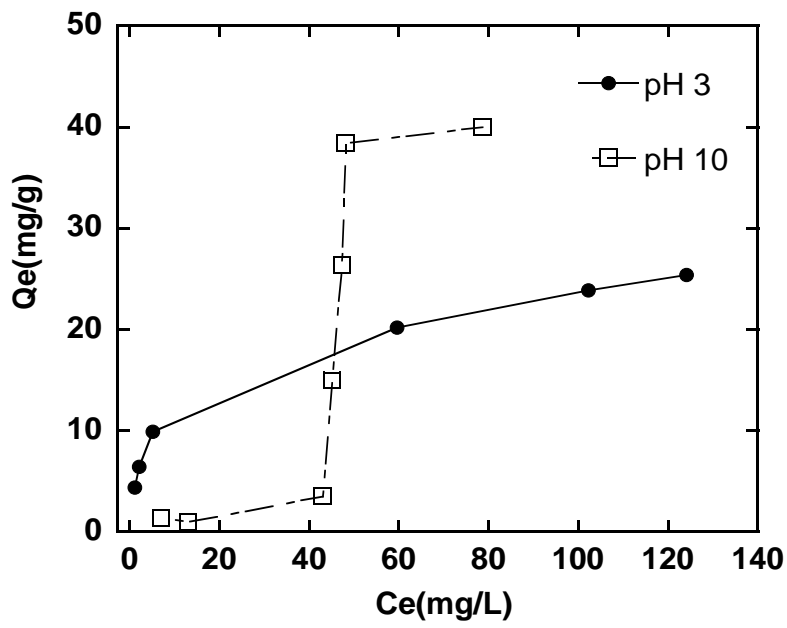

Figure 6. Adsorption isotherm of Bromothymol Blue on $\mathrm{TiO}_{2} \mathrm{P} 25$ at different $\mathrm{pH}$. 


$$
\begin{gathered}
\frac{C_{e}}{q_{e}}=\frac{1}{K_{L} q_{m}}+\frac{C_{e}}{q_{m}} \\
\ln q_{e}=\ln K_{F}+\frac{1}{n \ln C_{e}}
\end{gathered}
$$

where $C_{e}$ is the equilibrium concentration of adsorbate, $q_{e}$ is the equilibrium adsorption capacity, $K_{L}$ is the Langmuir adsorption equilibrium constant, $q_{m}$ is the maximum adsorption capacity, $K_{F}$ is the Freundlich adsorption equilibrium constant, and $n$ is the constant of Freundlich adsorption. The Langmuir and Freundlich adsorption isotherms that are obtained using the above two equations are given in Figure 7.

As seen in the figure, good linear correlation is obtained for both adsorbate MO and BTB, indicating that our experimental data fit well with Langmuir adsorption model. In the case of Methyl Orange the correlation coefficient $\left(\mathrm{R}^{2}\right)$ for Langmuir and Freundlich adsorption isotherm were 0.9987 and 0.9354 , respectively. This indicates that the experimental data has a better fit with the Langmuir adsorption model. As discussed above, $\mathrm{MO}$ is adsorbed on the $\mathrm{TiO}_{2}$ surface by electrostatic attraction at $\mathrm{pH}$ 3. Thus, the homogeneous nature of surface hydroxyl groups led to Langmuir type adsorption. This implies that the adsorbed layer is monolayer coverage.

In the case of Bromothymol Blue the correlation $\left(\mathrm{R}^{2}\right)$ for Langmuir and Freundlich adsorption isotherm were 0.9921 and 0.9047 , respectively, which also indicate that the experimental data has a better fit with the Langmuir adsorption model. For the Bromothymol Blue, the only factor that contributes to the adsorption is the hydrogen bond Vs a homogenous positive charged hydroxyl group on the surface of $\mathrm{TiO}_{2}$. This implies also that the adsorbed layer is monolayer coverage.

To compare the affinity of different adsorbates to the titane sorbent, the Langmuir isotherm parameters were investigated. Table 1 shows the value of Langmuir isotherm for Methyl Orange and Bromothymol Blue at $\mathrm{pH}$ 3. As the results shown the values of constant b show a very higher affinity of $\mathrm{MeO}$ toward ti$\tan$ surface and this may due to van der Waals attraction between them, at $\mathrm{pH} 3$.

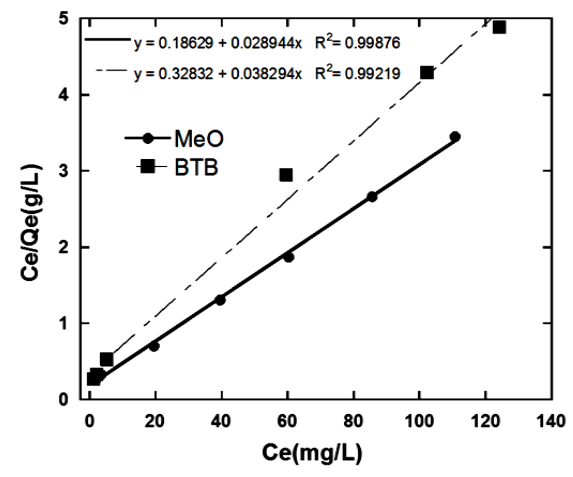

(a)

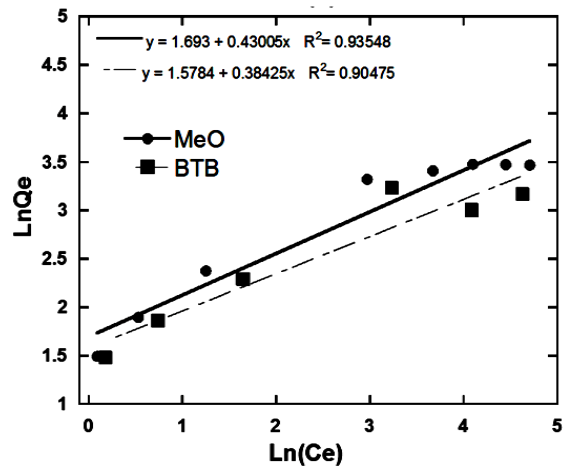

(b)

Figure 7. Langmuir adsorption isotherms (a) and Freundlich adsorption isotherms (b) for Methyl Orange and Bromothymol Blue at $\mathrm{pH} 3$. 
Table 1. Langmuir isotherm constant for Methyl Orange and Bromothymol Blue.

\begin{tabular}{|c|c|c|}
\hline $\mathrm{BBT}$ & $\mathrm{qm}$ & 39.8 \\
\hline \multirow{5}{*}{$\mathrm{MeO}$} & KL & 71.4 \\
\hline & $\mathrm{b}=1 / \mathrm{KL}$ & 0.014 \\
\hline & $\mathrm{qm}$ & 34.6 \\
\hline & KL & 6.66 \\
\hline & $\mathrm{b}=1 / \mathrm{KL}$ & 0.155 \\
\hline
\end{tabular}

\subsection{Photocatalytic Degradation and Kinetic Study}

The degradation experiments by UV irradiation are expected to follow the pseudo-first-order kinetics with respect to the dye concentration in the bulk solution. Therefore the kinetics of the study can be analyzed by the Langmuir- Hinshelwood model [32] [33]:

$$
-\frac{\mathrm{d} C}{\mathrm{~d} t}=K_{r} K_{a} \cdot \frac{C}{1+K_{a} C}
$$

where $-\left(\frac{\mathrm{d} C}{\mathrm{~d} t}\right)$ is the photocatalytic oxidation rate, $K_{r}$ is the photocatalytic oxidation rate constant, $K_{a}$ is the adsorption equilibrium constant, and $t$ is the reaction time. If the product of $K_{a}$ and $C$ is significantly smaller than 1 , the above equation can be simplified to a first-order reaction:

$$
-\frac{\mathrm{d} C}{\mathrm{~d} t}=K_{r} K_{a} \cdot C
$$

Consequently an integrated form of Equation (4) can be represented as follows:

$$
\ln \left(\frac{C_{0}}{C}\right)=K t
$$

where $K=K_{r} K_{a}$ is the apparent rate constant in $\min ^{-1}$. The kapp value can be obtained by plotting $\ln \left(C_{0} / C\right)$ vs. $t$.

Since the $\mathrm{pH}$ is a main factor that contributes the photodegradation of dyes on titanium dioxide [34], the photodegradation of Methyl Orange and Bromothymol Blue was studied as a function of $\mathrm{pH}$, acidic and basic medium.

Methyl Orange

The photocatalytic degradation of Methyl Orange in acidic and basic medium ( $\mathrm{pH} 3$ and 10) are illustrated in Figure 8.

The two curves show a similar trend, the concentration of Methyl Orange decrease as time increase in acidic and basic medium. The data at irradiation 0 corresponds to the remaining pollutant concentration after one hour of stirring in the dark. Consequently, it gives access to adsorption capability which is previously studied with the adsorption isotherm.

A weak adsorption of Methyl Orange on $\mathrm{TiO}_{2}$ surface at $\mathrm{pH} 10$ are observed since there is a very slight diminution of the Methyl Orange concentration after 


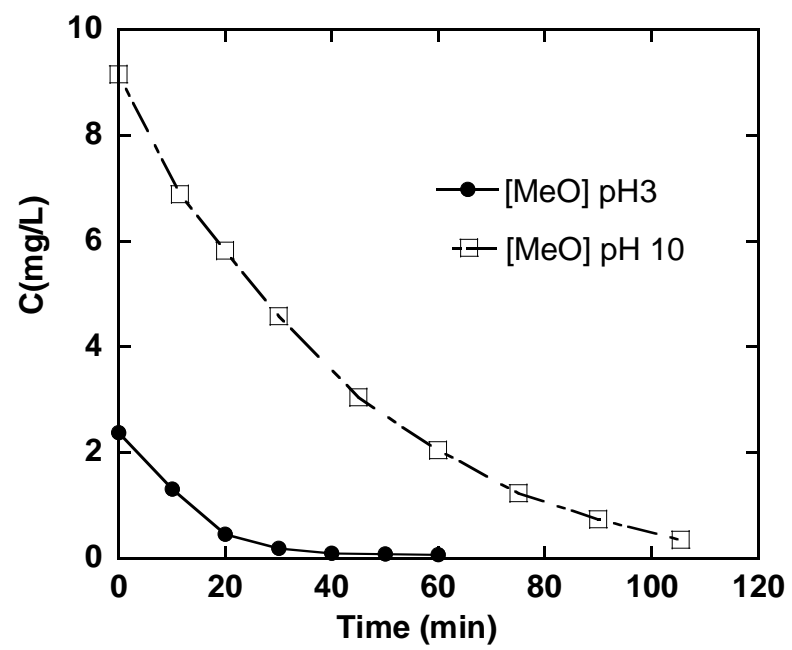

Figure 8. Photocatalytic degradation of Methyl Orange at $\mathrm{pH} 3$ and $\mathrm{pH} 10$ as a function of the time of irradiation for the Titanium P25.

60 min of dark period. On the other hand, in acidic medium ( $\mathrm{pH} 3)$, the high diminution of the concentration of Methyl Orange at $t=0$, reflect the high adsorption amount of Methyl Orange molecules on titane surface at this $\mathrm{pH}$.

These results are consistent with those showed by the adsorption isotherm of Methyl Orange presented in Figure 5, where the quantity of Methyl Orange adsorbed at $\mathrm{pH} 3$ is much higher than those at $\mathrm{pH} 10$.

Based on the zeta potential variation of Titanium dioxide as a function of $\mathrm{pH}$, and the pKa of Methyl Orange, at $\mathrm{pH} 10$ all the species bear a negative charge. The titanium dioxide is negatively charged (zeta potential of ca. $-40 \mathrm{mV}$ see Figure 4) while the acidity constant of Methyl Orange is equal to 3.75. The small value of the pollutants adsorbed amounts can be explained by the electrostatic repulsions between the pollutant and the catalysts.

In kinetic study, Methyl Orange photodegradation proceeds more favorably at pH 3 [20]. The degradation of Methyl Orange occurs after 60 mins. The difference in the photocatalytic activity can be related to the difference in adsorption amount between two pHs [25].

The photodegradation kinetic of Methyl Orange was then investigated with the results shown in Figure 10. This figure represents the evolution of $\operatorname{Ln}(\mathrm{C} 0 / \mathrm{C})$ as a function of time. The linear evolution confirms that the degradation of Methyl Orange by titanium dioxide follow the pseudo-first order.

The calculated the pseudo-first-order rate constant $\mathrm{K} 1$ for $\mathrm{pH} 3$ was 0.07 , and K2 0.02 for $\mathrm{pH} 10$.

Bromothymol Blue

Figure 9 represents the photocatalytic degradation of Bromothymol Blue at $\mathrm{pH} 3$ and $\mathrm{pH} 10$.

The BTB concentrations ( $\mathrm{C} 0$ ) of $\mathrm{pH} 3$ and $\mathrm{pH} 10$ after the dark period are close to the initial one $(10 \mathrm{mg} / \mathrm{L})$. This indicates a low adsorbed amount of Bromothymol Blue on the catalyst surface during the dark period.

This behavior can be verified from the adsorption isotherm that shows a low 


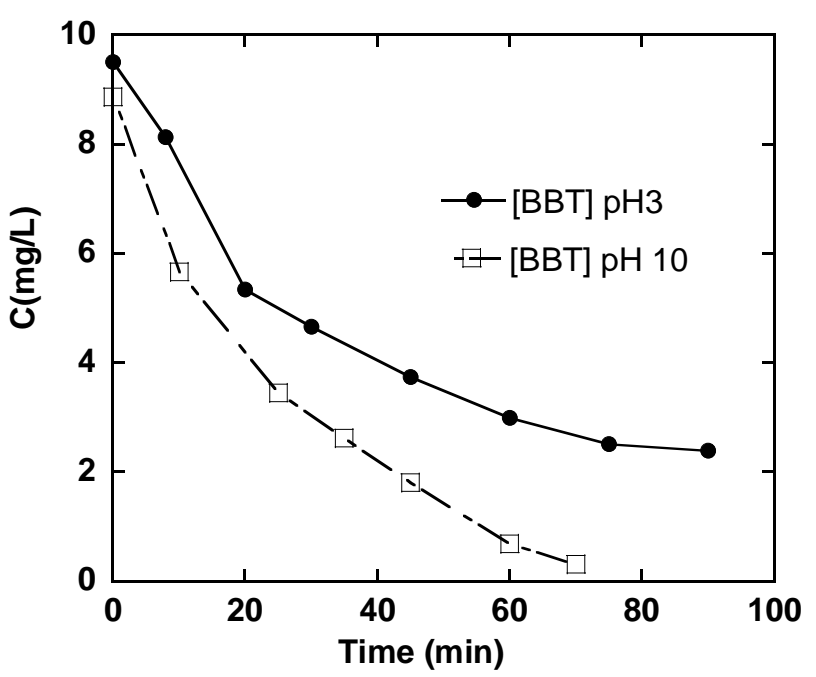

Figure 9. Photocatalytic degradation of Bromothymol Blue at $\mathrm{pH} 3$ and $\mathrm{pH} 10$ as a function of the time of irradiation for the Titanium P25.

adsorption amount on the $\mathrm{TiO}_{2}$ surface for low concentrations (see Figure 6).

In this figure each curve shows a similar trend. The bulk concentration of Bromothymol Blue decreases as time increases. The photocatalytic performance is affected by the $\mathrm{pH}$ of the solution. In basic medium ( $\mathrm{pH} 10)$, the Bromothymol Blue solution is almost fully degraded within 70 min under UV light. This time increases for acidic medium.

In order to investigate the kinetic parameters, a plot of $\operatorname{Ln}(\mathrm{C} 0 / \mathrm{C})$ versus the irradiation time $(t)$ is reported in Figure 10.

The linear evolution confirms that the degradation of Methyl Orange by titanium dioxide follow the pseudo-first order.

The calculated the pseudo-first-order rate constant $\mathrm{K} 1$ for $\mathrm{pH} 3$ was 0.01 , and K2 0.04 for $\mathrm{pH} 10$.

Table 2 shows the different kinetic parameters and the adsorption percentage of Methyl Orange and Bromothymol Blue in acidic and basic medium.

In acidic medium the adsorption percentage of $\mathrm{MO}$ on $\mathrm{TiO}_{2}$ surface is $76 \%$ which is much higher than that of BTB at the same $\mathrm{pH}$. This result was also verified with the constant value of Langmuir isotherm, where the constant $b$ shows a very high affinity of MO toward titan surface relative to that of BTB. In the same context the value of kinetic constant of $\mathrm{MO}$ at $\mathrm{pH} 3$ is too much bigger than that of BTB at the same $\mathrm{pH}$, which indicate that the adsorption on the surface is the main factor that affect the degradation of $\mathrm{MO}$ and $\mathrm{BTB}$ on the titane surface at pH 3 [34].

In acidic medium the adsorption percentage of $\mathrm{MO}$ on $\mathrm{TiO}_{2}$ surface is $76 \%$ which is much higher than that of BTB at the same $\mathrm{pH}$. This result was also verified with the constant value of Langmuir isotherm, where the constant $b$ shows a very high affinity of MO toward titan surface relative to that of BTB. In the same context the value of kinetic constant of $\mathrm{MO}$ at $\mathrm{pH} 3$ is too much bigger than that of BTB at the same $\mathrm{pH}$, which indicate that the adsorption on the surface is the 


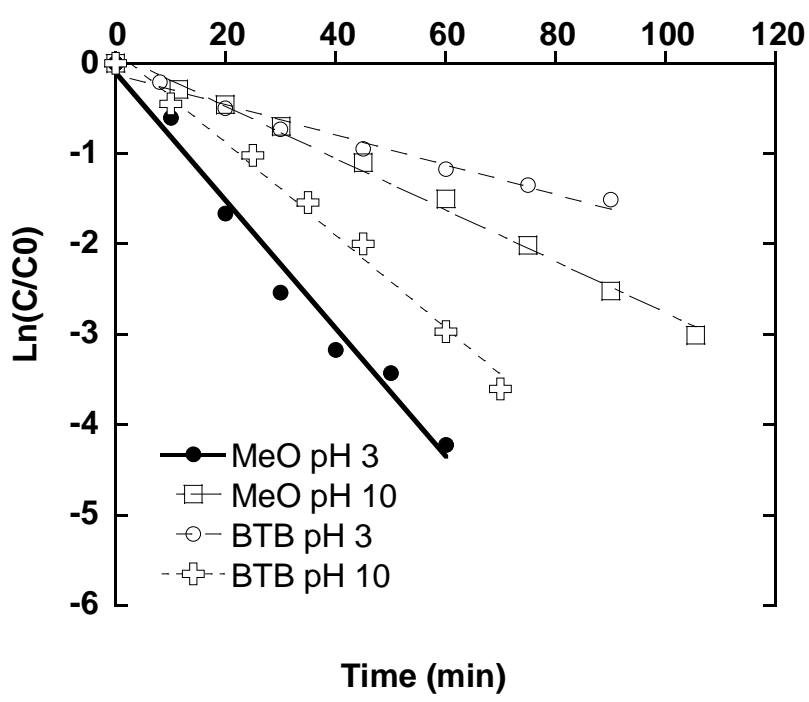

Figure 10. Pseudo-first kinetics of Methyl Orange and Bromothymol Blue at $\mathrm{pH} 3$ and $\mathrm{pH} 10$.

Table 2. Kinetic parameters and adsorption percentages of Methyl Orange and Bromothymol Blue in acidic and basic medium.

\begin{tabular}{ccccc}
\hline & \multicolumn{2}{c}{ MO } & \multicolumn{2}{c}{ BTB } \\
\hline & $\mathrm{pH} \mathrm{3}$ & $\mathrm{pH} \mathrm{10}$ & $\mathrm{pH} \mathrm{3}$ & $\mathrm{pH} \mathrm{10}$ \\
\hline $\mathrm{K}$ & 0.07 & 0.02 & 0.01 & 0.04 \\
\% Adsorption & $76 \%$ & $11.5 \%$ & $5 \%$ & $11 \%$ \\
\hline
\end{tabular}

main factor that affect the degradation of MO and BTB on the titane surface at pH 3 [34].

In basic medium the adsorption percentage of $\mathrm{MO}$ and $\mathrm{BTB}$ are considered equal and negligible, due to the repulsion between dye molecule and titania surface as we explained before. If we compare the kinetic constant of MO and BTB, we noticed that the degradation of BTB occurs two times faster than that of MO. These results reveal that the adsorption on the surface is not the only factor that affects the photodegradation of organic molecules.

The variation of chemical structure of the molecule as a function of $\mathrm{pH}$ can vary the bond energy of its structure [36] and consequently its stability. The efficiency of $\mathrm{OH}$ radical liberated from the bulk of $\mathrm{TiO}_{2}$ can be affected by the stability of structure [37]. However, in basic medium the BB-structure of BTB is negatively charged on its $\mathrm{SO}_{3}$ function group, with 3 rings and 1 hydroxyl group, two bromines and ketone group. On the other hand, Methyl Orange has an azo ion structure in basic medium which is contain two rings connected by nitrogen group, and negative charge on $\mathrm{SO}_{3}$ function.

\section{Conclusions}

In this paper we compare the adsorption affinity of Methyl Orange and Bromothymol Blue on $\mathrm{TiO}_{2} \mathrm{P} 25$ nanoparticles on acidic and basic medium. The nano- 
particles are characterized by XRD, and Zetaphorometer, the UV/visible spectroscopie was used to follow the variation of the concentration of dyes during photodegradation.

The adsorption isotherm was performed at two pHs ( 3 and 10), then the photodegradation process under UV light was compared for the two dyes toward titania nanoparticles at different $\mathrm{pHs}$.

In acidic medium, the adsorption was the main factor that affects the photodegradation where the rate constant of the degradation was compatible with the adsorption percentage. In basic medium, the chemical structure of organic molecule changes due to variation of $\mathrm{pH}$, which reflected by a dramatic decreasing of adsorption percentage, and for the same values of adsorption percentage between $\mathrm{MO}$ and BBT we noticed a big differences in the rate constant of degradation process, this result indicates that the adsorption was no more the main factor that affects the photodegradation of molecules. The chemical structure of the molecule becomes effective at this stage and may play an essential role in the efficiency of $\mathrm{OH}$ radical for the degradation of organic molecule.

\section{Acknowledgements}

The author is gratefully acknowledge the support of this research by the "The Research Laboratory of Materials, Catalysis, Environment and Analytical Methods (MCEMA)" under the supervision of Prof. Joumana Toufaily and Tayssir Hamieh.

\section{References}

[1] Zhou, Q., Fang, Z., Li, J. and Wang, M. (2015) Applications of $\mathrm{TiO}_{2}$ Nanotube Arrays in Environmental and Energy Fields: A Review. Microporous and Mesoporous Materials, 202, 22-35.

[2] Jain, R. and Sikarwar, S. (2008) Photodestruction and COD Removal of Toxic Dye Erioglaucine by $\mathrm{TiO}_{2}$-UV Process: Influence of Operational Parameters. International Journal of Physical Sciences, 3, 299-305.

[3] Srinivasan, A. and Viraraghavan, T. (2010) Decolorization of Dye Wastewaters by Biosorbents: A Review. Journal of Environmental Management, 91, 1915-1929.

[4] Khouni, I., Marrot, B., Moulin, P. and Ben Amar, R. (2011) Decolourization of the Reconstituted Textile Effluent by Different Process Treatments: Enzymatic Catalysis, Coagulation/Flocculation and Nanofiltration Processes. Desalination, 268, 27- 37.

[5] Soares, P.A., Silva, T.F.C.V., Ramos Arcy, A., Souza, S.M.A.G.U., Boaventura, R.A.R. and Vilar, V.J.P. (2016) Assessment of AOPs as a Polishing Step in the Decolourisation of Bio-Treated Textile Wastewater: Technical and Economic Considerations. Journal of Photochemistry and Photobiology A: Chemistry, 317, 26-38.

[6] Saratale, R.G., Saratale, G.D., Chang, J.S. and Govindwar, S.P. (2011) Bacterial Decolorization and Degradation of Azo Dyes: A Review. Journal of the Taiwan Institute of Chemical Engineers, 42, 138-157.

[7] Guesh, K., Mayoral, Á., Márquez-Álvarez, C., Chebude, Y. and Díaz, I. (2016) Enhanced Photocatalytic Activity of $\mathrm{TiO}_{2}$ Supported on Zeolites Tested in Real Wastewaters from the Textile Industry of Ethiopia. Microporous and Mesoporous Materials, 225, 88-97. 
[8] Rostami-Vartooni, A., Nasrollahzadeh, M., Salavati-Niasari, M. and Atarod, M. (2016) Photocatalytic Degradation of Azo Dyes by Titanium Dioxide Supported Silver Nanoparticles Prepared by a Green Method Using Carpobrotus acinaciformis Extract. Journal of Alloys and Compounds, 689, 15-20.

[9] Pang, Y.L., Lim, S., Ong, H.C. and Chong, W.T. (2014) A Critical Review on the Recent Progress of Synthesizing Techniques and Fabrication of $\mathrm{TiO}_{2}$-Based Nanotubes Photocatalysts. Applied Catalysis A: General, 481, 127-142.

[10] Lee, S.-Y. and Park, S.-J. (2013) $\mathrm{TiO}_{2}$ Photocatalyst for Water Treatment Applications. Journal of Industrial and Engineering Chemistry, 19, 1761-1769.

[11] Barakat, M.A. (2011) Adsorption and Photodegradation of Procion Yellow H-EXL Dye in Textile Wastewater over $\mathrm{TiO}_{2}$ Suspension. Journal of Hydro-Environment Research, 5, 137-142.

[12] Li, S.-X., Zheng, F.-Y., Cai, W.-L., Han, A.-Q. and Xie, Y.-K. (2006) Surface Modification of Nanometer Size $\mathrm{TiO}_{2}$ with Salicylic Acid for Photocatalytic Degradation of 4-Nitrophenol. Journal of Hazardous Materials, 135, 431-436.

[13] Nagaveni, K., Sivalingam, G., Hegde, M.S. and Madras, G. (2004) Photocatalytic Degradation of Organic Compounds over Combustion-Synthesized Nano- $\mathrm{TiO}_{2}$. Environmental Science \& Technology, 38, 1600-1604. https://doi.org/10.1021/es034696i

[14] Homlok, R., Takács, E. and Wojnárovits, L. (2013) Degradation of Organic Molecules in Advanced Oxidation Processes: Relation between Chemical Structure and Degradability. Chemosphere, 91, 383-389.

[15] Parra, S., Olivero, J. and Pulgarin, C. (2002) Relationships between Physicochemical Properties and Photo-Reactivity of Four Biorecalcitrant Phenylurea Herbicides in Aqueous $\mathrm{TiO}_{2}$ Suspension. Applied Catalysis B: Environmental, 36, 75-85.

[16] Herrmann, J.-M. (2005) Heterogeneous Photocatalysis: State of the Art and Present Applications in Honor of Pr. R.L. Burwell Jr. (1912-2003), Former Head of Ipatieff Laboratories, Northwestern University, Evanston (Ill). Topics in Catalysis, 34, 4965. https://doi.org/10.1007/s11244-005-3788-2

[17] Gaya, U.I. and Abdullah, A.H. (2008) Heterogeneous Photocatalytic Degradation of Organic Contaminants over Titanium Dioxide: A Review of Fundamentals, Progress and Problems. Journal of Photochemistry and Photobiology C: Photochemistry Reviews, 9, 1-12.

[18] Blin, J.-L., Stébé, M.-J. and Roques-Carmes, T. (2012) Use of Ordered Mesoporous Titania with Semi-Crystalline Framework as Photocatalyst. Colloids and Surfaces A: Physicochemical and Engineering Aspects, 407, 177-185.

[19] Su, Y., et al. (2013) Enhanced Photodegradation of Methyl Orange with $\mathrm{TiO}_{2} \mathrm{Na}$ noparticles Using a Triboelectric Nanogenerator. Nanotechnology, 24, Article ID: 295401. https://doi.org/10.1088/0957-4484/24/29/295401

[20] Al-Qaradawi, S. and Salman, S.R. (2002) Photocatalytic Degradation of Methyl Orange as a Model Compound. Journal of Photochemistry and Photobiology A: Chemistry, 148, 161-168.

[21] Nagegowda, P. and Basavaiah, K. (2005) Simple and Practicable Methods for the Determination of Astemizole in Pharmaceuticals Using Bromate-Bromide and Two Dyes. Journal of the Brazilian Chemical Society, 16, 821-826. https://doi.org/10.1590/S0103-50532005000500022

[22] Klotz, E., Doyle, R., Gross, E. and Mattson, B. (2011) The Equilibrium Constant for Bromothymol Blue: A General Chemistry Laboratory Experiment Using Spectroscopy. Journal of Chemical Education, 88, 637-639. 
https://doi.org/10.1021/ed1007102

[23] Toma, F.-L., et al. (2006) Microstructure and Environmental Functionalities of $\mathrm{TiO}_{2}$-Supported Photocatalysts Obtained by Suspension Plasma Spraying. Applied Catalysis B: Environmental, 68, 74-84.

[24] Zaki, M.I., Hasan, M.A., Al-Sagheer, F.A. and Pasupulety, L. (2001) In Situ FTIR Spectra of Pyridine Adsorbed on $\mathrm{SiO}_{2}-\mathrm{Al}_{2} \mathrm{O}_{3}, \mathrm{TiO}_{2}, \mathrm{ZrO}_{2}$ and $\mathrm{CeO}_{2}$ : General Considerations for the Identification of Acid Sites on Surfaces of Finely Divided Metal Oxides. Colloids and Surfaces A: Physicochemical and Engineering Aspects, 190, 261-274.

[25] Cerrato, G., Marchese, L. and Morterra, C. (1993) Structural and Morphological Modifications of Sintering Microcrystalline $\mathrm{TiO}_{2}$ : An XRD, HRTEM and FTIR Study. Applied Surface Science, 70, 200-205.

[26] Martra, G., et al. (1999) The Role of $\mathrm{H}_{2} \mathrm{O}$ in the Photocatalytic Oxidation of Toluene in Vapour Phase on Anatase $\mathrm{TiO}_{2}$ Catalyst: A FTIR Study. Catalysis Today, 53, 695702.

[27] Connor, P.A., Dobson, K.D. and McQuillan, A.J. (1999) Infrared Spectroscopy of the $\mathrm{TiO}_{2} /$ Aqueous Solution Interface. Langmuir, 15, 2402-2408. https://doi.org/10.1021/la980855d

[28] Zhao, J., Milanova, M., Warmoeskerken, M.M.C.G. and Dutschk, V. (2012) Surface Modification of $\mathrm{TiO}_{2}$ Nanoparticles with Silane Coupling Agents. Colloids and Surfaces A: Physicochemical and Engineering Aspects, 413, 273-279.

[29] Asuha, S., Zhou, X.G. and Zhao, S. (2010) Adsorption of Methyl Orange and Cr(VI) on Mesoporous $\mathrm{TiO}_{2}$ Prepared by Hydrothermal Method. Journal of Hazardous Materials, 181, 204-210.

[30] Langmuir, I. (1918) The Adsorption of Gases on Plane Surfaces of Glass, Mica and Platinum. Journal of the American Chemical Society, 40, 1361-1403.

https://doi.org/10.1021/ja02242a004

[31] Hashemian, S., Ardakani, M.K. and Salehifar, H. (2013) Kinetics and Thermodynamics of Adsorption Methylene Blue onto Tea Waste/CuFe2O4 Composite. American Journal of Analytical Chemistry, 4, 1-7. https://doi.org/10.4236/ajac.2013.47A001

[32] Hoffmann, M.R., Martin, S.T., Choi, W. and Bahnemann, D.W. (1995) Environmental Applications of Semiconductor Photocatalysis. Chemical Reviews, 95, 69-96. https://doi.org/10.1021/cr00033a004

[33] Tian, M., Adams, B., Wen, J., Matthew Asmussen, R. and Chen, A. (2009) Photoelectrochemical Oxidation of Salicylic Acid and Salicylaldehyde on Titanium Dioxide Nanotube Arrays. Electrochimica Acta, 54, 3799-3805.

[34] Kassir, M., et al. (2015) Improvement of the Photocatalytic Activity of $\mathrm{TiO}_{2}$ Induced by Organic Pollutant Enrichment at the Surface of the Organografted Catalyst. Colloids and Surfaces A: Physicochemical and Engineering Aspects, 485, 73-83.

[35] Zhang, L., et al. (2014) Adsorption-Photocatalytic Degradation of Methyl Orange over a Facile One-Step Hydrothermally Synthesized $\mathrm{TiO}_{2} / \mathrm{ZnO}-\mathrm{NH}_{2}-\mathrm{RGO}$ Nanocomposite. RSC Advances, 4, 48703-48711. https://doi.org/10.1039/C4RA09227A

[36] Huang, F., Chen, L., Wang, H., Feng, T. and Yan, Z. (2012) Degradation of Methyl Orange by Atmospheric DBD Plasma: Analysis of the Degradation Effects and Degradation Path. Journal of Electrostatics, 70, 43-47.

[37] Lü, X., Ma, H., Zhang, Q. and Du, K. (2013) Degradation of Methyl Orange by UV, $\mathrm{O}_{3}$ and $\mathrm{UV} / \mathrm{O}_{3}$ Systems: Analysis of the Degradation Effects and Mineralization Mechanism. Research on Chemical Intermediates, 39, 4189-4203.

https://doi.org/10.1007/s11164-012-0935-9 
Submit or recommend next manuscript to SCIRP and we will provide best service for you:

Accepting pre-submission inquiries through Email, Facebook, LinkedIn, Twitter, etc. A wide selection of journals (inclusive of 9 subjects, more than 200 journals)

Providing 24-hour high-quality service

User-friendly online submission system

Fair and swift peer-review system

Efficient typesetting and proofreading procedure

Display of the result of downloads and visits, as well as the number of cited articles Maximum dissemination of your research work

Submit your manuscript at: http://papersubmission.scirp.org/

Or contact msce@scirp.org 